\title{
SURPRISE ATTACK
}

Written under the auspices of the Jaffee Center for Strategic Studies,

Tel-Aviv University 



\title{
SURPRISE ATTACK
}

\section{The Victim's Perspective}

\author{
With a New Preface
}

\section{Ephraim Kam}

Harvard University Press

Cambridge, Massachusetts

London, England 
Copyright (C) 1988, 2004 by Ephraim Kam

All rights reserved

Printed in the United States of America

Second printing, 2004

First Harvard University Press paperback edition, 2004

Library of Congress Cataloging-in-Publication Data

Kam, Ephraim, 1941-

Surprise attack : the victim's perspective / Ephraim Kam.

p. $\mathrm{cm}$.

Bibliography: p.

Includes index.

ISBN 0-674-85745-3 (alk. paper)

ISBN 0-674-01354-9 (pblk.)

1. Surprise. 2. Military art and science. 3. International

relations. 4. Preemptive attack (Military science). 5. Military

history, Modern-20th century. I. Title.

U163.K27 1988

88-15395

$355.4^{\prime} 3$ - dc19 
To Matia 
